\title{
Ocena letala C-27J Spartan, za gašenje gozdnih požarov
}

Jaša Saražin, Gozdarski inštitut Slovenije, Oddelek za gozdno tehniko in ekonomiko Božidar Lovro Birkić, Gozdarski inštitut Slovenije, Oddelek za gozdno tehniko in ekonomiko

Objavljeno na spletu 23.01.2022 (https://doi.org/10.20315/IG.2022.0008)

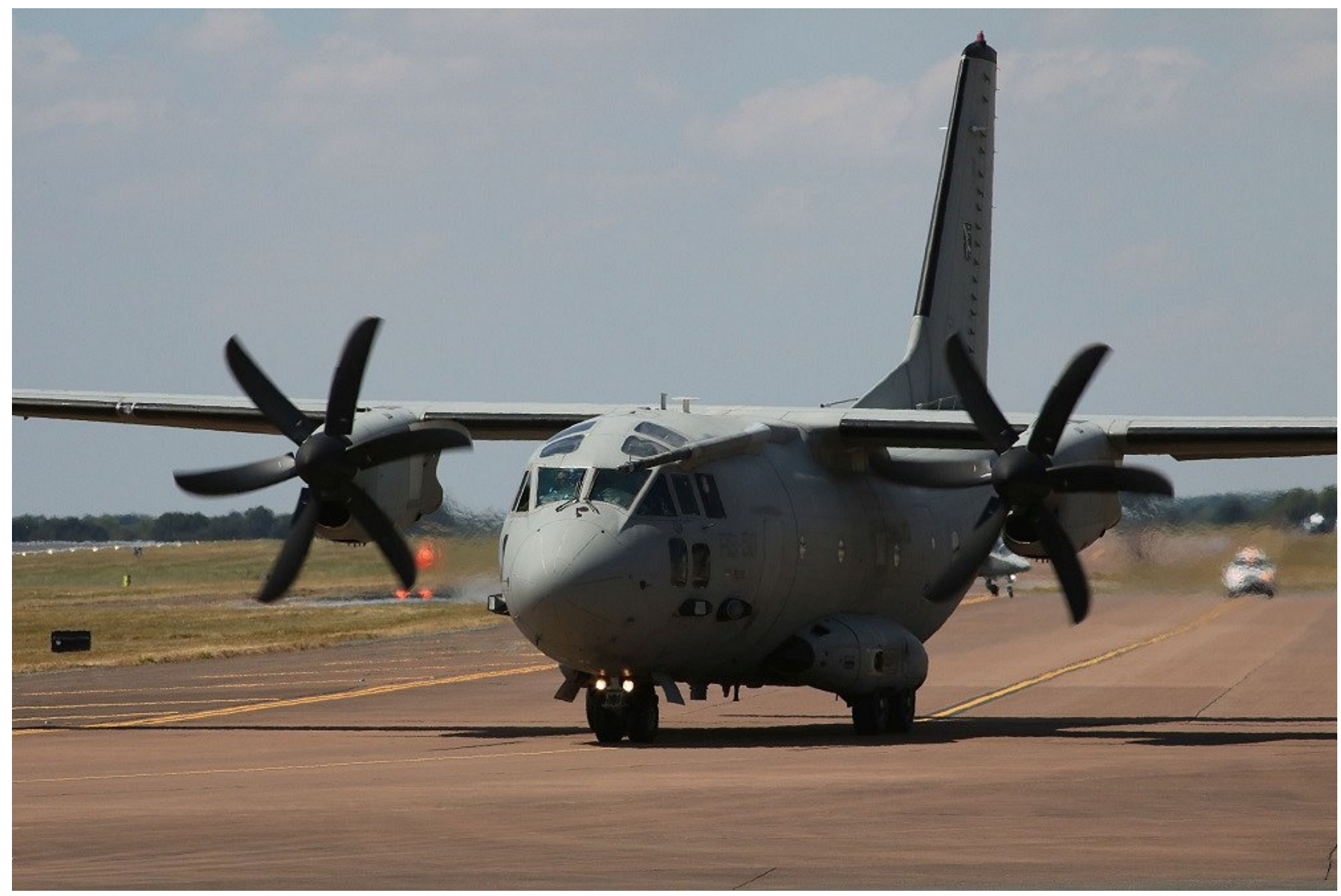

Slika 1: Vojaško taktično transportno letalo C-27J Spartan (Foto: Borut Podgoršek, MORS)

Nedavno je Ministrstvo za obrambo Republike Slovenije (MORS) podpisalo pogodbo o nakupu novega vojaškega letala C-27J Spartan, ki se bo lahko uporabljalo tudi za gašenje požarov v naravi.

Letalo C-27J Spartan italijanskega proizvajalca Leonardo je v prvi vrsti vojaško taktično transportno letalo, namenjeno nalogam $v$ sklopu zavezništa NATO, poleg tega pa omogoča izvedbo tudi drugih nalog (GOV, 2022). V tem prispevku bomo predstavili nekaj osnovnih tehničnih značilnosti tega letala ter ga primerjali $z$ drugimi letali, ki se uporabljajo za gašenje požarov $v$ naravi v naši neposredni bližini. Gašenja iz zraka se poslužujemo pri večjih požarih v naravnem okolju. Helikopterji in letala so 
odlična dopolnitev kopeskih sil. V Sloveniji trenutno lahko iz zraka požare gasijo vojaški helikopterji Bell 412 in Cougar ter letalo Pilatus PC-6. V sosednjih državah pa so poleg pisane flote reševalnih in vojaških helikopterjev, najpogostejša namenska letala Canadair in Air Tractor.

\section{Gašenje požarov z letalom C-27J Spartan}

Brez prilagoditve letala, se lahko v njegov tovorni del namesti do 6 »Guardian « zabojev za gašenje. Vsak zaboj se na tleh napolni s 1000 I gasilne vode (običajno z dodatkom retardanta), kar pomeni skupno 6000 I gasilnega sredstva. Letalo C-27] Spartan ima v svoji konfiguraciji sistem za natančno odmetavanje tovora na nizkih in visokih višinah, zato je možno natančno odmetavanje posameznih zabojev, ali pa celotne skupine zabojev. Zaboj se po izmetu odpre, gasilno sredstvo iz 7 zaporedno odmetanih zabojev (na Spartanu jih je 6), pa lahko pokrije površino $550 \mathrm{~m}$ x $65 \mathrm{~m}$. Prazen zaboj tehta okvirno 45 kg, je zložljiv ter biorazgradljiv. Ker se voda iz zabojev sprošča z zamikom, se gašenje na ta nič lahko izvaja iz večjih višin, v primerjavi z ostalimi letali. Slabost tega je nižja natančnost, prednost pa večja varnost letala in možnost gašenja tudi ponoči, ko je potrebno klasično gašenje iz zraka prekiniti (Caylym, 2022). S takim letalom C-27J Spartan in sistemom Guardian, so pripadniki Romunske vojske pomagali gasiti požara v Makedoniji, o katerem smo nedavno pisali (Saražin, 2021).

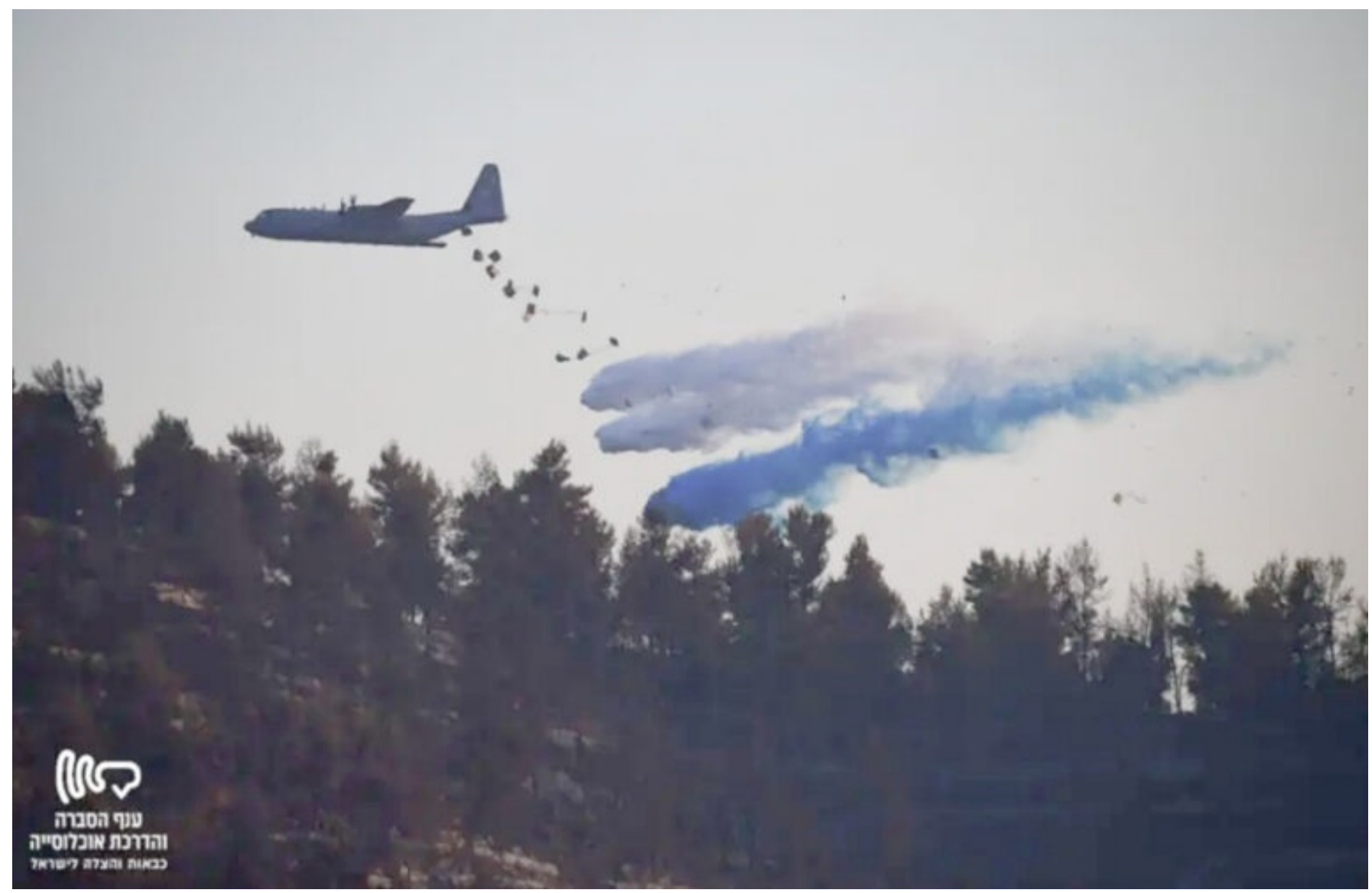

Slika 2: Gašenje vojaškega transportnega letala z uporabo sistema vodnih zabojev »Guardian« (vir: Fireaviation, 2022)

Za letalo C-27J Spartan je možno naročiti tudi poseben modul za gašenje požarov v naravnem okolju, ki pa po naših informacijah ni predmet aktualnega naročila. Modul je 9850 I velik rezervoar za gasilno sredstvo, ki se ga namesti v tovorni del letala ter omogoča klasičen izpust (Leonardo, 2020). 


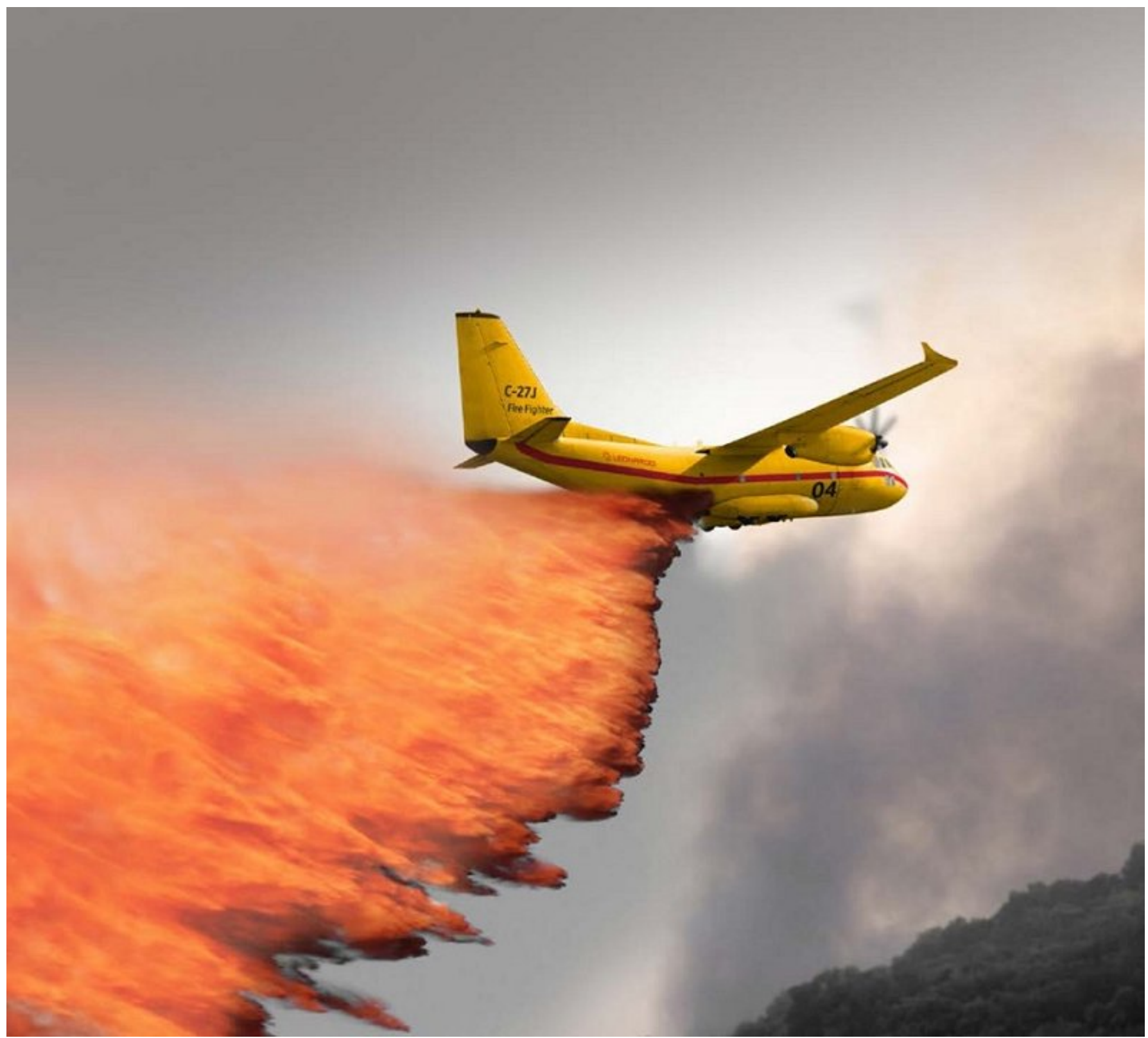

Slika 3: Letalo C-27J Spartan je mogoče opremiti tudi s posebnim modulom za gašenje požarov, ki lahko prevaža okvirno 10000 I gasilnega sredstva. Po naših informacijah ta modul ni predmet osnovnega nakupa letala MORS. (Vir: Leonardo, 2020)

Po zagotovilu MORS, bo lahko letalo C-27J Spartan, poleg iz glavnih letališč, izvajalo naloge gašenja tudi iz vseh primorskih letališč (Portorož, Divača, Postojna, Ajdovščina in Bovec; za ostala letališča nismo preverjali).

\section{Primerjava C-27J Spartan, Pilatus PC-6, Canadair CL-415 in Air Tractor AT 802A}

Čeprav ne letalo C-27J Spartan, ne Pilatus PC-6, nista namenski letali za gašenje požarov, smo izvedli njuno primerjavo z namenskima letaloma za gašenje požarov Canadair CL-415 in Air Tractor AT 802A, s kakršnima razpolaga Hrvaška ter številne druge sosednje države. Predstavitev osnovnih značilnosti letal so prikazane $v$ preglednici. 


\begin{tabular}{|c|c|c|c|c|}
\hline & C-27J Spartan & Pilatus PC-6 & Canadair CL-415 & $\begin{array}{c}\text { Air Tractor AT- } \\
802 \mathrm{~A} \\
\end{array}$ \\
\hline Dolžina (m) & 22,7 & 10,9 & 19,8 & 10,9 \\
\hline $\begin{array}{c}\text { Max skupna masa } \\
\text { (t) }\end{array}$ & 31,8 & 2,8 & 21,4 & 7,3 \\
\hline Nosilnost $(t)$ & 11,6 & 1,5 & np. & 4,2 \\
\hline Moč (kW) & 6916 & 507 & 3550 & 993 \\
\hline $\begin{array}{c}\text { Min / max hitrost } \\
(\mathrm{km} / \mathrm{h})\end{array}$ & $194 / 602$ & $107 / 244$ & $125 / 377$ & $146 / 350$ \\
\hline $\begin{array}{l}\text { Min dolžina steze } \\
\text { - max teža }(\mathrm{m})\end{array}$ & 580 & 400 & 840 & 610 \\
\hline $\begin{array}{c}\text { Gasilno sredstvo - } \\
\text { voda (I) }\end{array}$ & $6000(9850)$ & 800 & 6137 & 3000 \\
\hline Cena (mio $€$ ) & 72 & 2 & 26 & 3 \\
\hline
\end{tabular}

Preglednica: primerjava tehničnih značilnosti štirih letal. Podatki povzeti po (Air Tractor, 2022, Leonardo, 2020, MOHR, 2022, Slovenska vojska, 2022, UPHV, 2022)

Iz tabele lahko hitro ugotovimo, da je po svojih gabaritih letalo C-27J Spartan v grobem primerljivo z letalom Canadair CL-415; letalo Pilatus PC-6 pa z letalom Air Tractor AT-802A. Z uporabo sistema Guardian pri letalu C-27J Spartan, ostane precejšen del nosilnosti letala neizkoriščen, kljub temu, pa lahko nad požarišče odvrže enako količino vode, kot letalo Canadair CL-415, medtem ko je z uporabo posebnega modula ta bistveno večja.
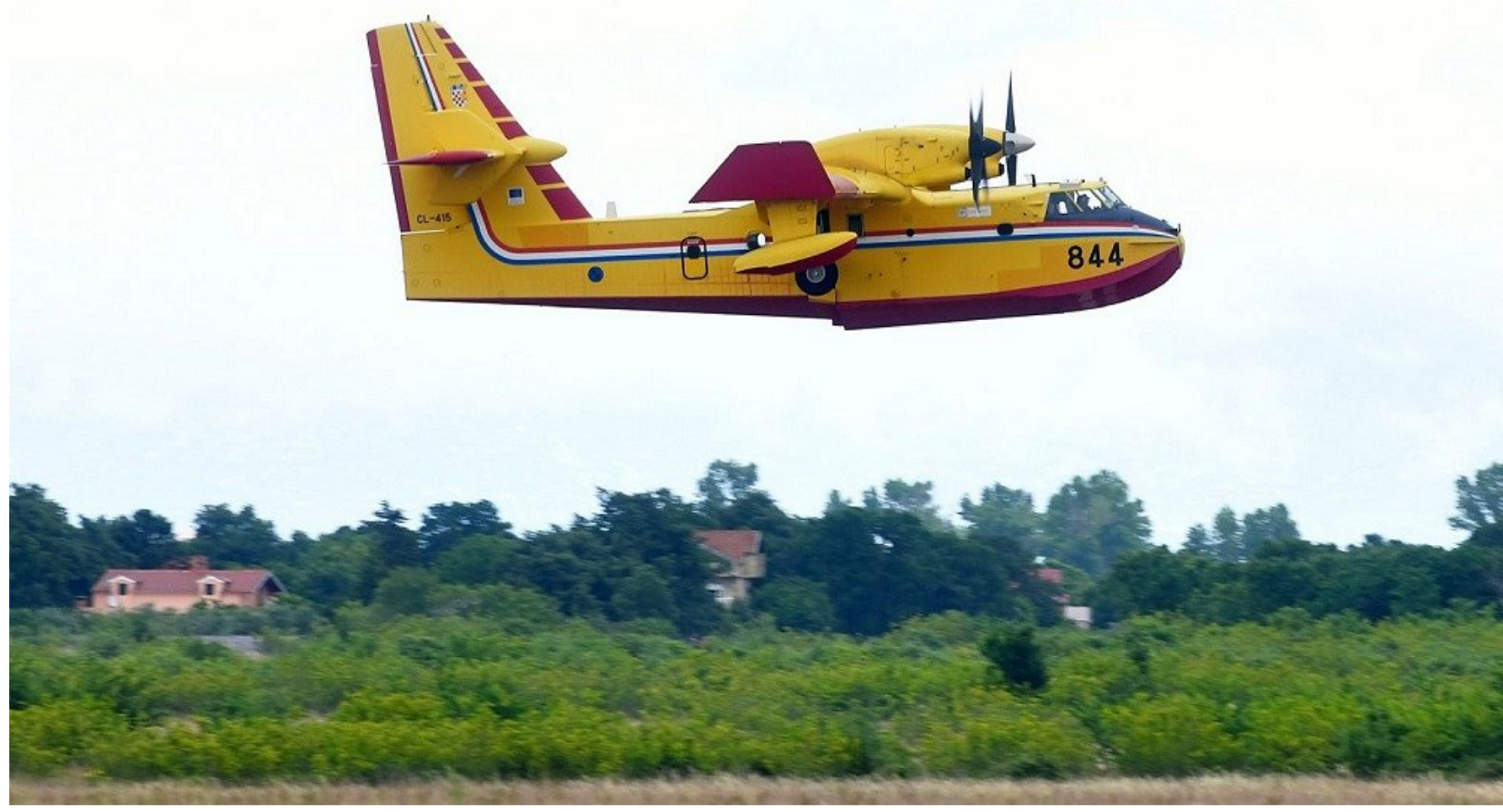
Amfibijski način delovanja, s katerim se ponaša Canadair CL-415, ter opcijsko tudi Air Tractor AT-802A, predstavlja prednost tih dveh letal v primeru delovaja v bližini večjih vodnih teles. $\vee$ primeru Slovenije, bi to bilo predvsem morje. Uporaba morske vode, pa je z ekološkega vidika, na boljših gozdnih rastiščih, škodljiva.

Pristajanje, polnjenje in vzletanje iz manjših letališč, ali večjih uravnanih travnih površin je resda bolj zamudno, v primerjavi z amfibijskim načinom delovanja. Ker pa je mreža tovrstnih primernih vzletišč solidno razporejena po območju Slovenije z večjo požarno ogroženostjo gozdov, bi letala lahko kljub temu izvedla precejšnje število naletov. Najmanjše zahteve za kvaliteto in dolžino vzletne steze ima letalo Pilatus PC-6. Sledita mu C-27J Spartan in Air Tractor AT-802A, medtem ko potrebuje Canadair CL-415 daljšo vzletno stezo (po naših ocenah bi Canadair CL-415 na primorskem, na klasičen način lahko deloval le z letališč Portorož in Ajdovščina ter pogojno Bovec).

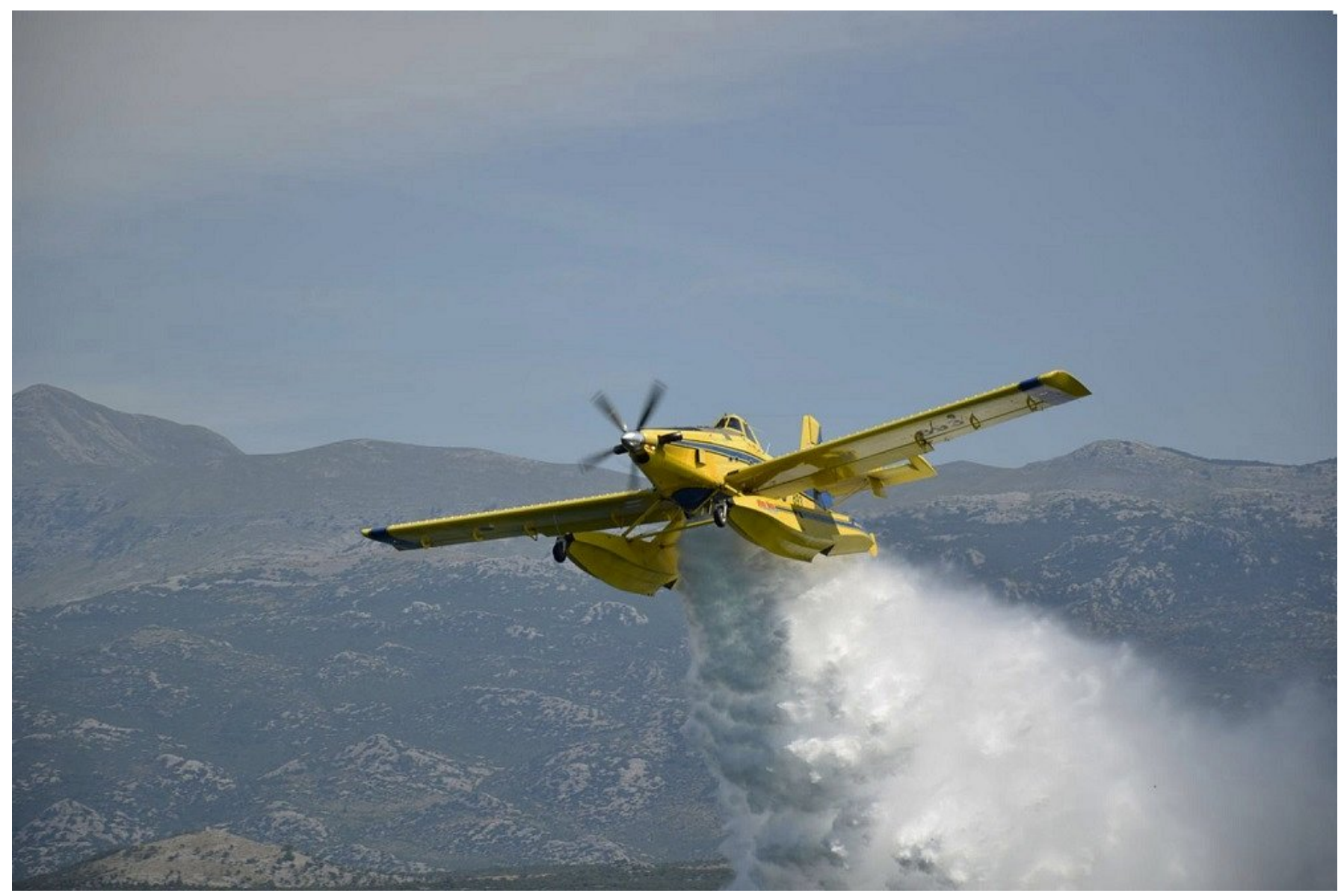

Slika 5: Manjše letalo Air Tractor lahko prevaža 3000 I gasilnega sredstva (Vir: MOHR,2022)

V kolikor bi Slovenska vojska kupovala letalo izključno z namenom gašenja požarov, bi avtorji prispevka svoj glas dali letalu Air Tractor. Ker so pa pri tokratnem nakupu v ospredju vojaške naloge verjamemo, da bo letalo C-27J Spartan lahko veliko prispevalo pri gašenju večjih požarov v naravnem okolju tako doma, kot tudi na misijah v tujini. 


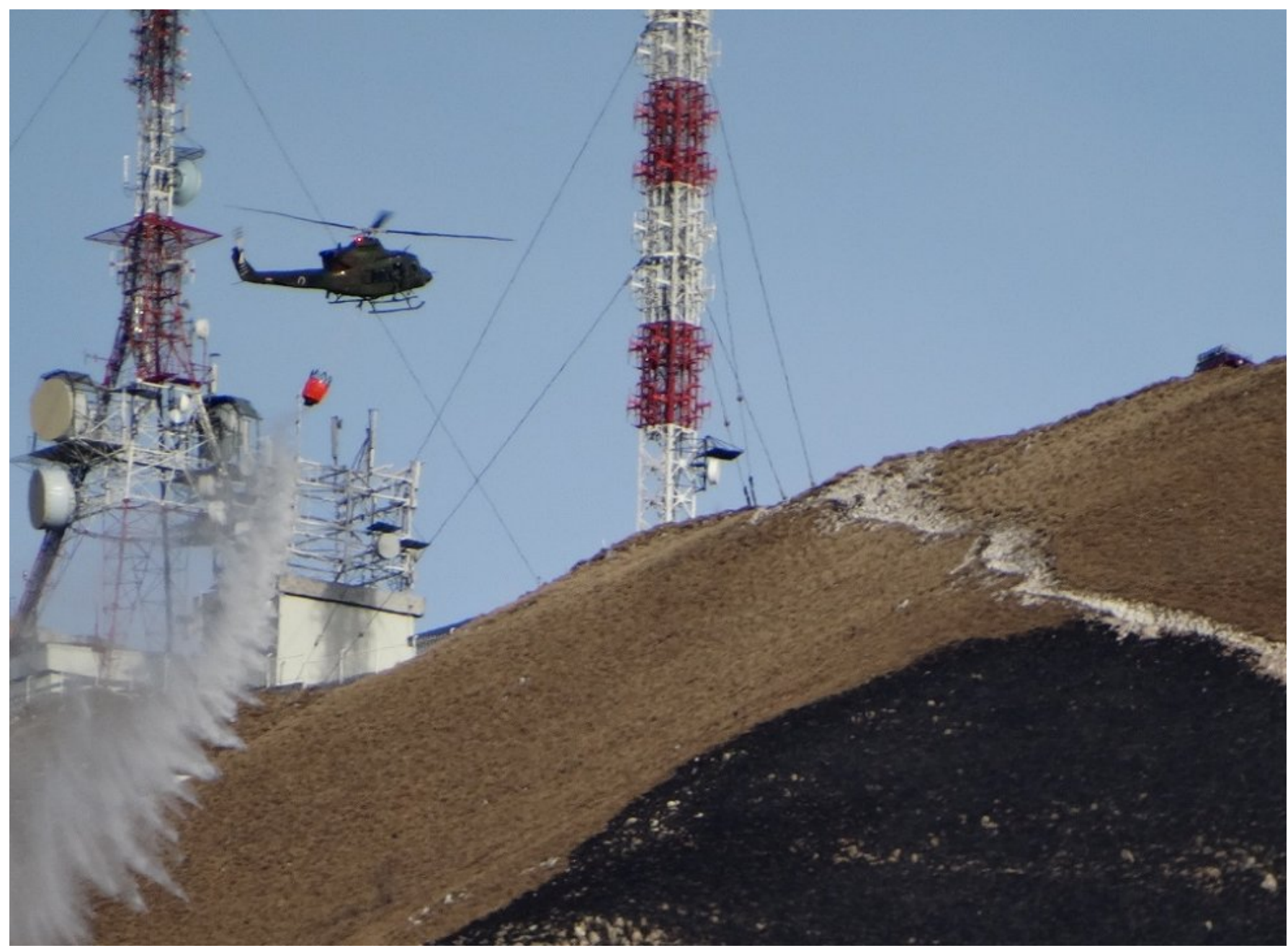

Slika 6: Za gašenje iz zraka so najbolj univerzalni helikopterji. Letos je helikopter Bell 412 Slovenske vojske gasil požar na Nanosu že 1. januarja (Foto: J. Saražin)

Literatura

- Air Tractor, tehnični podatki (https://airtractor.com/aircraft/at-802a/ - dostop, 3.1.2022)

- Caylym, »sistem Guardian« (https://www.caylym.com/guardian-drop-image-panel - dostop, 3.1.2022)

- Fireaviation - gašenje s sistemom Guardian (https://fireaviation.com/tag/caylym/ - dostop, 3.1.2022)

- GOV

(https://www.gov.si/zbirke/projekti-in-programi/varnost-za-vse/vlaganja-v-slovensko-vojsko/letal o/ - dostop, 3.1.2022)

- Leonardo, brošura $\quad$ C-27J Spartan, 2020 (http://www.leonardocompany.com/documents/20142/12775636/C-27J+Next+Gen_brochure_EN G.pdf?t=1610100772690 - dostop, 3.1.2022)

- MOHR (https://www.morh.hr - dostop, 3.1.2022)

- Saražin J. 2021. Požar v naravnem okolju v Severni Makedoniji je pogašen. InfoGozd: Skrbno z gozdom 2 (8): 6-8

- Slovenska vojska (https://www.slovenskavojska.si//oborozitev-in-oprema/letalstvo/ - dostop, 3.1.2022)

- UPVH (http://www.upvh.hr/u-gnijezdu-kanadera/ - dostop, 3.1.2022) 